\title{
Experimental/Computational Study of the Electrochemical Oxidation of Cyclooctatetraene in Protic Media. Solvent Effects.
}

\author{
Grayson Connors, Xin Wu, and Albert J. Fry* \\ Chemistry Department, Wesleyan University, Middletown, CT 06459
}

\section{SUPPORTING INFORMATION}

\section{Table of Contents}

General procedures

Experimental procedure for anodic oxidation of cyclooctatetraene in methanol

${ }^{1} \mathrm{H}$ NMR spectrum of 7-dimethoxymethyl-1,3,5-cycloheptatriene (3b).

${ }^{1} \mathrm{H}-{ }^{1} \mathrm{H}$ COSY spectrum of 7-dimethoxymethyl-1,3,5-cycloheptatriene (3b).

Cyclic voltammogram of cyclooctatetraene in methanol at a glassy carbon electrode; potentials measured to $\mathrm{Ag} / 0.1 \mathrm{M} \mathrm{AgNO}_{3}$ reference electrode 
General procedures: ${ }^{1} \mathrm{H}$ NMR and COSY spectra were recorded in $\mathrm{CDCL}_{3}$ on a Varian $300 \mathrm{MHz}$ Gemini spectrometer. Mass spectra were recorded on a Hewlett-Packard model 59988A gas chromatograph-mass spectrometer. Preparative glpc separations were carried out on a Gow-Mac model 580 thermal conductivity gas chromatograph.

Anodic oxidation of cyclooctatetraene in methanol. Cyclooctatetraene $(1.00 \mathrm{~g}, 9.6$ mmol) was added to a $0.1 \mathrm{M}$ solution of $\mathrm{LiBF}_{4}(0.95 \mathrm{~g})$ in $25 \mathrm{~mL}$ of $\mathrm{MeOH}$ in a $100-\mathrm{mL}$ three-necked round-bottom flask fitted with a carbon cloth anode and platinum mesh cathode. The solution was stirred at $0^{\circ} \mathrm{C}$ while a constant current of $100 \mathrm{~mA}$ was passed for a period of time corresponding to passage of two electrons per molecule of cyclooctatetraene (5.2 hours), during which time the color changed from yellow to dark brown and then black. The contents of the flask were poured into $100 \mathrm{~mL}$ of water and extracted with two separate portions of diethyl ether. The ether extracts were then transferred to a separatory funnel and washed with $50 \mathrm{~mL}$ of distilled water and $10 \mathrm{~mL}$ of brine. The organic layer was separated and dried over $\mathrm{NaSO}_{4}$. The crude product $(1.65 \mathrm{~g})$ was purified using gas chromatography. Analysis by GC indicated the presence of a major product $(95 \%)$. The compound was purified by preparative gas chromatography (glpc)) for spectral analysis. ${ }^{1} \mathrm{H}$ and COSY spectroscopy established the structure of the primary product as 7-dimethoxymethyl-1,3,5-cycloheptatriene (3b). ${ }^{1}$

${ }^{1}$ Cope, A. C.; Nelson, N. A.; Smith, D. S. J. Am. Chem. Soc. 1954, 76, 1100. 


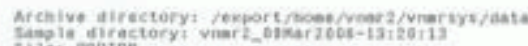

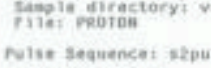

Nolse seanencent
solvent; cocis

nebrent temenciature

gevax, dolay 1,000 sec

Puise 13 .

Alain 24104 in

18 repotitions

obstive

Dath Fidoctist

Total tiee of oin, an sec

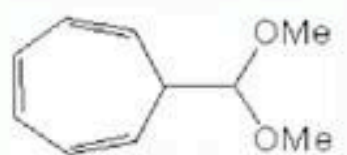

$3 b$

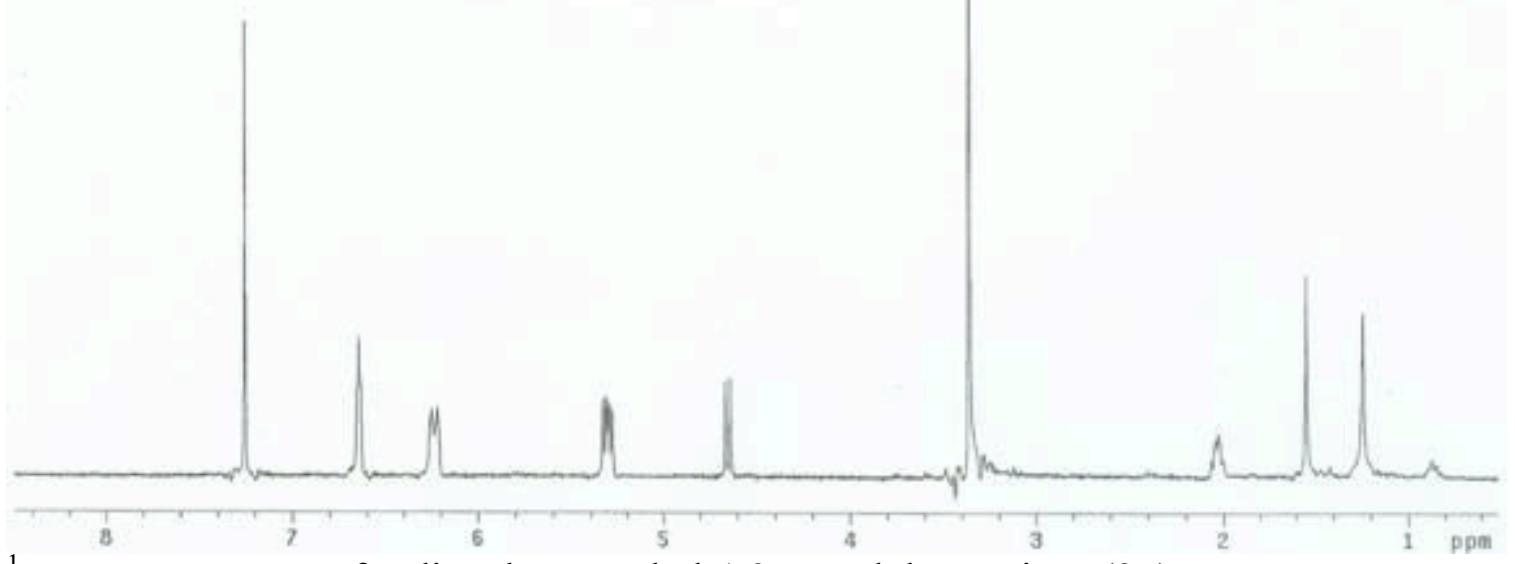

${ }^{1} \mathrm{H}$ NMR spectrum of 7-dimethoxymethyl-1,3,5-cycloheptatriene (3b). 

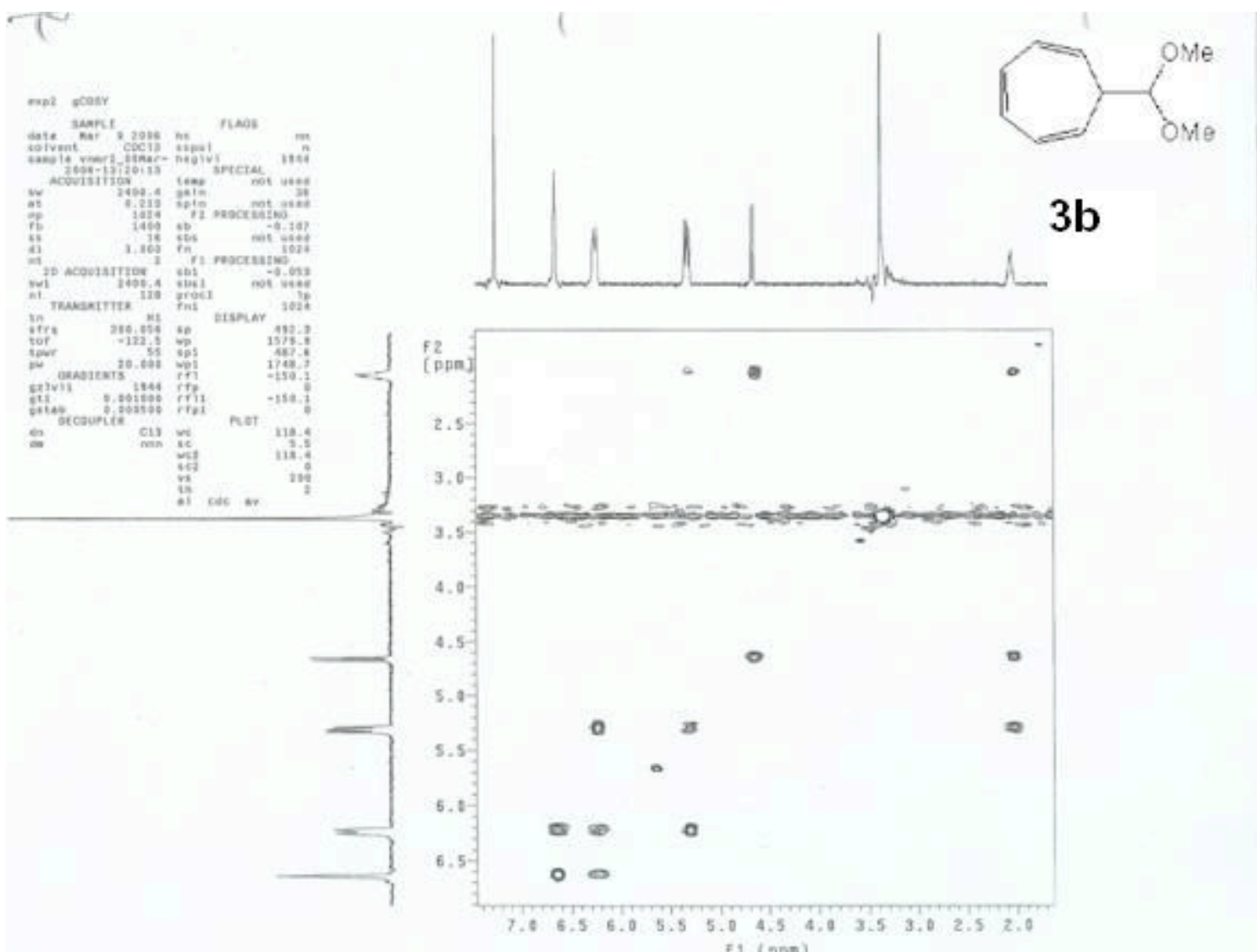

${ }^{1} \mathrm{H}-{ }^{1} \mathrm{H}$ COSY spectrum of 7-dimethoxymethyl-1,3,5-cycloheptatriene (3b). 


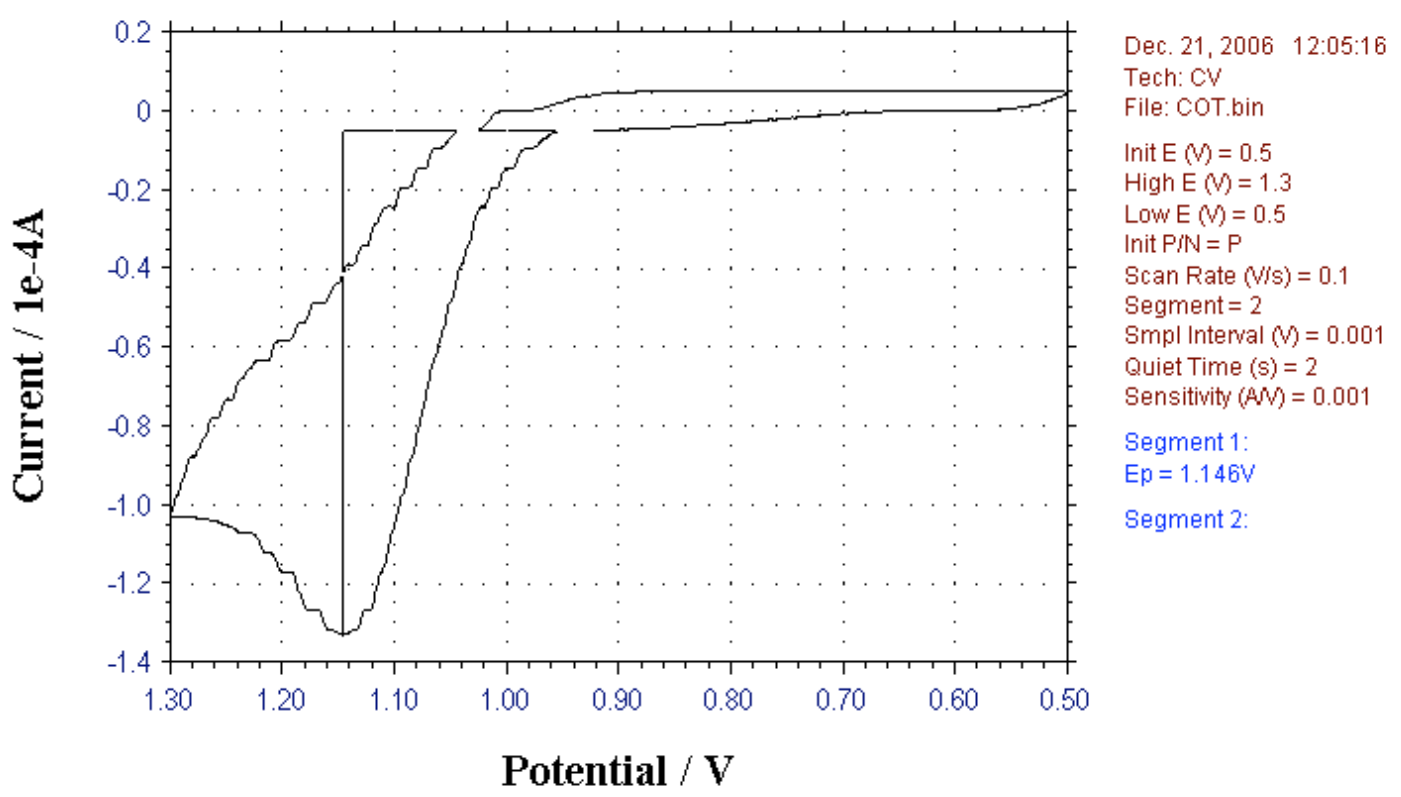

Cyclic voltammogram of cyclooctatetraene in methanol at a glassy carbon electrode; potentials measured to $\mathrm{Ag} / 0.1 \mathrm{M} \mathrm{AgNO}_{3}$ reference electrode (this electrode is $+0.35 \mathrm{~V}$ vs $\mathrm{SCE}$ ). 
Computational procedure. It was discovered that most structures, particularly the neutral species $\mathbf{2}, \mathbf{3}$, and $\mathbf{6}$, are capable of existing in several conformations of differing energies. The global minimum conformation was located using the GMMX search routine in PCMODEL 9.0 (Macintosh OSX). This molecular mechanics structure was then transferred to a computer (Puget Custom Computers, Seattle, WA) equipped with four parallel 64-bit AMD Opteron ${ }^{\circledR}$ processors sharing 4 GB of RAM. Computations were carried using the Gaussian '03 suite of programs. ${ }^{1}$

(1) Gaussian 03, Revision C.02, Frisch, M. J.; Trucks, G. W.; Schlegel, H. B.; Scuseria, G. E.; Robb, M. A.; Cheeseman, J. R.; Zakrezewski, V. G.; J. A. Montgomery, J.; Stratmann, R. E.; Burant, J. C.; Dapprich, S.; Millam, J. M.; Daniels, A. D.; Kudin, K. N.; Strain, M. C.; Farkas, O.; Tomasi, J.; Barone, V.; Cossi, M.; Cammi, R.; Mennucci, B.; Pomelli, C.; Adamo, C.; Clifford, S.; Ochterski, J.; Petersson, G. A.; Ayala, P. Y.; Cui, Q.; Morokuma, K.; Malick, D. K.; Rabuck, A. D.; Raghavachari, K.; Foresman, J. B.; Cioslowski, J.; Ortiz, J. V.; Stefanov, B. B.; Liu, G.; Liashenko, A.; Piskorz, P.; Komaroni, I.; Gomperts, R.; Martin, R. L.; Fox, D. J.; Keith, T.; Al-Laham, M. A.; Peng, C. Y.; Nanayakkara, A.; Gonzalez, C.; Challacombe, M.; Gill, P. M. W.; Johnson, B. G.; Chen, W.; Wong, M. W.; Andres, J. L.; Head-Gordon, M.; Replogle, E. S.; Pople, J. A.; Gaussian, Inc.: Pittsburgh,PA, 2003. 